\title{
FACILITY MANAGEMENT OF SMART BUILDINGS
}

\author{
J. PAŠEK* V. SOJKOVÁ \\ Department of Mechanics, Faculty of Applied Sciences, University of West Bohemia, \\ Univerzitni 8, 30614 Pilsen, Czech Republic \\ *E-mail: pasek@kme.zcu.cz
}

The current development of smart buildings is conditioned by the development of smart technologies, bringing many new phenomena into the construction industry that change ownership, user and management environments. The optimized and truly functional smart building already includes engineering and non-technical aspects, which must, however, be respected during all life cycles. This requires the emergence of completely new expertise or the extension of the existing expertise, including facility management. Smart buildings enable cost savings and facilitated operation to facility management. Moreover, smart buildings also contain significant multidisciplinarity, especially in pertaining technical areas. This requires the facility manager to monitor individual disciplines and ensure their interoperability and optimal functioning to meet the needs of building users.

This contribution is based on practical experiences and focuses on the analysis of the new demands that smart buildings require in management issues, the evaluation of synergies between smart buildings and efficient facility management for maximizing the use of the building and its sustainability. It also quantifies the benefits of facility management for the operation of smart buildings and their utility value, depending on the degree of integration of services.

Keywords: facility management, smart building, BSM, operating costs, intelligent system

\section{Introduction}

A smart building, compared to conventional buildings, should provide its owner and users with a number of premium benefits. Expectations toward the building are evolving over the time, while the construction and equipment of the building are subject to aging and wear. Ensuring the required parameters of smart buildings throughout their lifecycle involves systematic care. This includes, on the one hand, careful preparation within the building planning and the subsequent implementation phase and, on the other hand, highly professional management and maintenance during operation. In all phases, the facility manager plays a key role.

The contemporary building of the 21 st century must (in addition to architectural, technical and environmental qualities) display a high degree of flexibility and usefulness. All these parameters have to be monitored continuously. The responsibility for the implementation of building monitoring as well as the analysis of monitored data often is attached to the facil- ity manager's responsibilities. The common practice shows that the possibilities of building optimization are decreasing with the degree of advancement of its realization. The highest implementation possibilities are therefore during the project preparation, especially at the beginning. Figure 1 illustrates the decrease of cost influence throughout the progress of the planning and operation phases of buildings. At the point in time just before the start of the construction works the amount and structure of future operating costs is virtually fixed up to $80 \%$. In the operation phase, only about $20 \%$ of the building's operating costs can be affected (while $80 \%$ of the overall costs are regularly attached to the operational phase).

It might not be the rule in many countries, but facility managers should be included in the design teams that prepare the building from the very beginning; This also applies to the reconstruction and construction modifications of the buildings. In the case of smart buildings, the involvement of a facility manager in the design team is a critical necessity. Thereby, the facility manager not only represents the interests

This is an open-access article distributed under the terms of the Creative Commons Attribution-NonCommercial 4.0 International License (https://creativecommons.org/licenses/by-nc/4.0/), which permits unrestricted use, distribution, and reproduction in any medium for non-commercial purposes, provided the original author and source are credited, a link to the CC License is provided, and changes - if any - are indicated. 


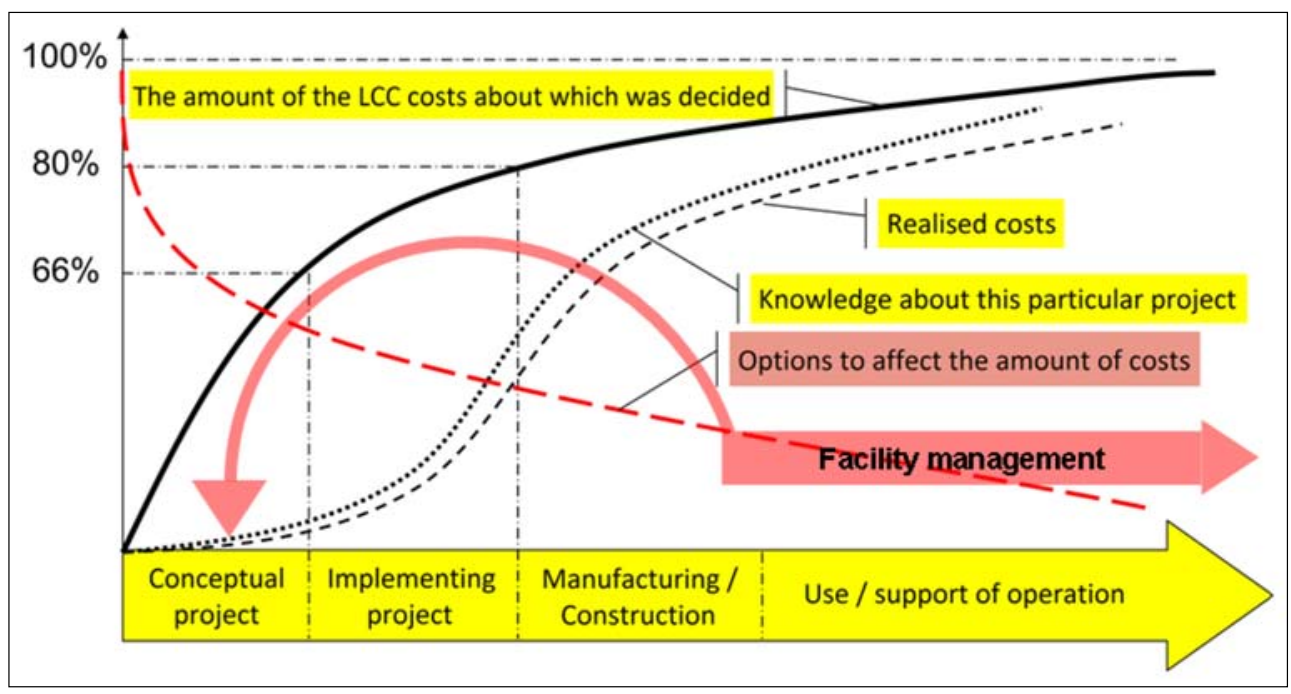

Fig. 1. Graph of the development of the impact on the overall life cycle cost of the construction [1]

of the investor (the future owner), but also of the future occupants. If the facility manager just takes over the already completed construction, he/she only has a very limited range of possibilities to influence the efficiency of the building costs during its lifecycle. For a truly professional facility manager, such non-optimal procedures are difficult to accept. This is due to the fact that a number of significant optimization measures on behalf of both building owner and future occupants cannot be fulfilled satisfactorily or at feasible impact on operating cost.

The principle of planned (preventive) maintenance has not currently been sufficiently extended in the use phase of the building. Most maintenance of buildings and their equipment is still being addressed as an evoked need that focuses on removing obvious manifestations and disorders, not on their causes. As a result, there is an increase in repair frequency and maintenance costs. As opposed to preventive maintenance, the cost of repairs can be up to four times higher than necessary. In addition, uncoordinated interventions in the operation of the building and necessary interruptions affect the comfort of building use [2]. For smart buildings, such a situation is totally unacceptable. Facility managers must eliminate such risks in conjunction with other components (especially the suppliers of smart systems) to prevent such situations.

\section{Smart building policy}

The concept of smart building can be described in many ways, principally including technical means, services and system solutions for meeting the needs of building owners and users, including their anticipation and reaction to their transformations over time. This creates a multiparametric environment, including integrated management of building management, security, and building management, including requirements for optimizing operating costs, and energy management, ensuring the quality of the indoor environment and maintaining the technical condition and building value. Each of these items contains several subgroups of parameters, all of which must consistently respect the demands of owners and users and their development over time. Therefore, the building must maintain its inherent "intelligence" in the long run, without changing the parameters and ideally increase its quality. This applies to all types of buildings, for example, residential, administrative, public, industrial, and takes into account the requirements for their specific purpose.

The needs of owners and users of smart buildings partly conform and are partly contradictory. Owners' preferences particularly include:

- minimizing acquisition costs;

- minimizing operating costs;

- minimizing energy costs;

- minimizing repair and reconstruction costs;

- maximizing the return on investment of the building;

- continuous conservation or increase in construction value (investment protection);

- maximizing the level of security of the building and its users.

From this overview, the crucial importance of the financial demands of buildings is obvious. The user (tenant) of the building in their own interest does not need to interfere with the above-mentioned interests of the owner, but he also prefers:

- flexibility of leased spaces;

- the quality of the indoor environment that contributes to achieving the desired comfort of use or to increasing work productivity;

- maximizing security level. 


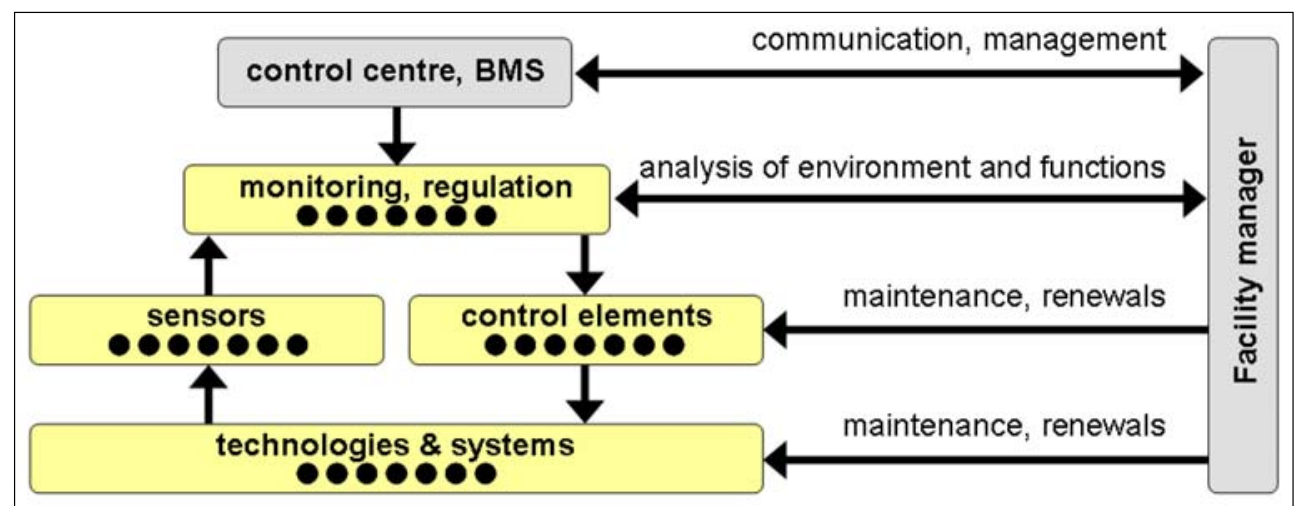

Fig. 2. Function principle of Building Management System (BMS) in relation to performance of facility management. (Source: authors)

In order to achieve the claims of users, the owner must usually spend a certain part of the financial gain on the rental of the building's interior. In view of all the 3 requirements of the building user, it is necessary to suppress the emphasis on "minimization" of all types of costs incurred by the owner during the construction, existence and operation of the building and to monitor their "optimization". The interests of both parties must be monitored and ensured by the facility manager, not only during its use but ideally during its preparation, projection and realization.

Individual technologies, or even only partial elements of a building intelligence, are usually supplied by different vendors or suppliers as part of the implementation or maintenance of the building. Each of the individual technologies must function flawlessly in an autonomous mode as well as in the management of sub-groups and central management of the building's operation. Sub-groups are involved with control systems of selected technologies, which ensure the achievement of individual operational requirements of the building. For example:

- optimization of energy management - power system management, heating, ventilation, cooling, air conditioning, lighting, shading technology, external sources (weather forecasting, etc.);

- fire safety of buildings and users - fire safety system, ventilation, lighting, lifts, security system, power system control;

- user safety - security system, person entry system, indoor CCTV circuit, lifts, lighting.

As can be seen from these examples, some autonomous technologies are integrated into more than one operating group, resulting in a single multisystem central controlling all the groups and therefore all technologies through their control systems. Individual autonomous technologies, respectively their control systems have to be parameterized for the needs of building operations but are centrally monitored and managed through a single BMS (Building Management
System) communication and visualization platform, including remote access to information. The purpose of BMS is to monitor and control individual technologies, alarming in the event of atypical occurrences and archiving of interim data (see Fig. 2). To respond to the displayed data, the operator has to be subordinate to the facility manager.

In addition to the systems involved in the BMS platform, additional elements of the human factor, such as security, cleaning, maintenance, IT services, accounting and external services, etc., which the facility manager must also manage and the results of their activities, must also be included for the optimal functioning of the smart building evaluate and optimized for the benefit of owners and users. All interventions need to be projected into the BIM (Building Information Modelling/Management) platform, the application of which should be a matter of course in the case of smart buildings from the beginning of the construction. Stanford University's Centre for Integrated Facilities Engineering examined 32 projects using BIM [3]. As a result of the more efficient data handling and coordination of the participating components, there was a significant shortening of the planning and implementation phase and the more efficient management of such properties. An important effect is also to save up to $40 \%$ off-budget and up to $10 \%$ of total costs as a result of eliminating collisions in pre-implementation and implementation phases. For smart buildings, BIM's financial benefits can be expected to be even higher.

\section{Facility management in smart buildings}

The subject of facility manager activity in the modern concept of building management is very wide and is expanding (in the case of smart buildings). In general, technical asset management, coordination and integrated management of direct support services for building users are included [4]. The Facility management (FM) area can be grouped according to the client's requirements, and they can be included together 
into two main groups, which are not a sharp boundary - the two groups mutually intertwine (see Fig. 3):

1) Space and Infrastructure - so-called "hard services", i.e. space management, space utilization, management and optimization of the workplace, technical management of buildings, energy management, waste management, indoor and outdoor cleaning.

2) People and Organizations - so-called "soft services", i.e. health, hygiene, safety and security, internal services (boarding, receptions, meeting rooms, secretarial services, etc.), ICT, internal logistics (archive services, internal mail, mail service, transport services, car service, etc.).

The International Facility Management Association (IFMA) states that facility management includes principles of business administration, architecture, humanities and technical sciences. Its aim is to achieve the long-term sustainability of the use of the building the optimal arrangement and use of the interior space, ensuring the functional and efficient functioning of the technical equipment, the quality of the internal environment and other user needs.

Last aim, but not least, the objective of facility management is to achieve a high quality indoor environment while ensuring the maximum efficiency of the energy and resources spent on the operation of the building. In principle, there is no difference in whether it is a residential, administrative or industrial building or a complex of buildings. Essential is the quality support of the primary activity of the client (subject of business), through the efficient use of his assets. Responsibility for these requirements should be taken by the facility manager as early as in the project preparation phase of a new building or reconstruction of the existing building - It should therefore be part of the design team and actively influence the emerging project.

In the case of the lifecycle of a smart building, the goal remains the same, but the level of responsibility for the function of the operating systems involved in the benefits of a smart building compared to the standard building - especially the high flexibility and usefulness of the building, the superior quality of the indoor environment and high operational efficiency. The technologies that provide these parameters can number into the hundreds, the network of which is considerably larger and more specialized when compared to the standard building. However, in the event of a failure of one of the technologies, the usability and security of the entire building is compromised, which is not necessarily fatal for a standard building. In addition to the quantifiable economic consequences of such an event, this can also be associated with non-financial impacts, such as loss of reputation for the owner.

With regard to the range of smart building's facility management services, it is clear that the facility manager is not an individual person but a team of professionals covered by a manager, directly responsible to the owner or CEO. Based on past experiences with the management of smart buildings and their complexity, it is quite common that the requirements of a lay proprietor of a building are contrary to his interests. As a result, the facility manager's responsibility must be not only high professional standing, but also the ability to defend the interests of the owner and their own opinions.

\section{Facility management for smart buildings}

The performance of facility management in smart building environments is expanded beyond standard

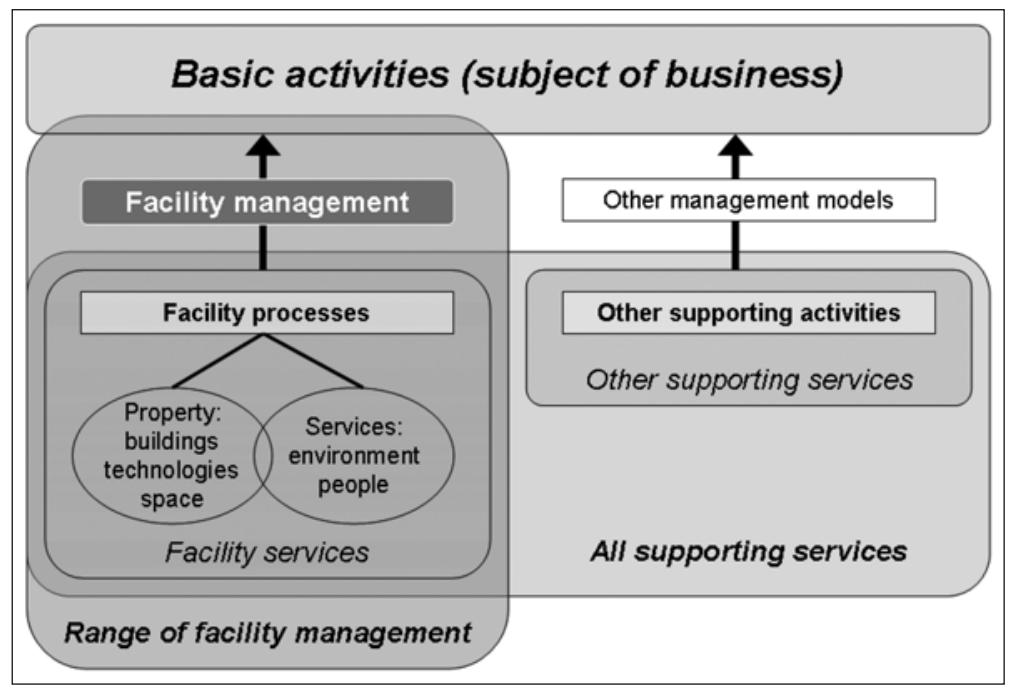

Fig. 3. Structure and activities of facility management and other supporting services. (Source: authors, modified from [4]) 
buildings to BMS platform operations. The BMS system and its graphical visualization of parameters is an effective tool for facility managers to get an overview of the current operational values of the building and the function respectively setting the individual systems, while allowing the parameters to be changed and responding to current needs. In view of the difficulty of performing the work, the facility manager must strive to maximize the usability of the BMS. Fully functional BMS significantly simplify the operation of smart buildings and facility management, especially in the area of central monitoring and control of all technologies involved in the platform. On the basis of practical experience, the following advantages can be defined in particular:

- unification of control of different types of technological equipment;

- remote control of technologies without physical presence on the device;

- the possibility of centralized interventions in the system in the event of a situation in the building or the needs of its users;

- storing information about actions taken by individual users;

- reducing the time and cost of monitoring the functionality of building technology in 24/7 regime.

However, practical experiences with the management of smart buildings points out some of the negatives that threaten the functionality of these buildings with possible high financial impacts. In particular, the management of large smart buildings or their groups is associated with the following risks, which need to be minimized:

- due to its size and structure, several operators are involved with BMS; in case of problems caused by improper handling, it may be difficult to trace the responsible person who caused the accident; risk elimination can be achieved either by consistent logging of users or by reducing operator stations to a minimum;

- if BMS is plugged into a technology whose system incorrectly implements a communications protocol or is inadequately configured by the vendor, the functionality of the entire BMS may be compromised e.g. by unavailability of some key functions in the BMS control interface or by overloading the BMS visualization server with a large number of absurd messages; elimination can be ensured by requiring thorough testing and reconfiguration of all new devices in the test environment before they are connected to the technology network;

- due to the diversity of systems and system data management solutions provided by different vendors, technical complications arise to prevent configuration and automatic back-up of the BMS system status; elimination is very difficult;

- the huge amount of data stored in the BMS virtually prevents manual selection of information for reporting and processing; the system must be equipped with a special system for automating these operations and intelligent data filtering and transmission between BIM and BMS.

Even in the case of smart buildings management, it is necessary to consistently see that the management systems are unable to monitor the technical condition of building structures; the degree of utilization of their commercial areas, etc. At the same time, they cannot monitor and evaluate the actual situation on the real estate market as well as the development of building users' needs. For this reason, the facility manager must continue to provide smart buildings with functions and activities common to so-called standard buildings that are based on human activities - questionnaire surveys among users, visual construction research using mobile instrumentation, market monitoring, financial analysis, communication with authorities, communication with suppliers, etc. The main activity is to link the conclusions from these activities to the actual results produced by the BMS and BIM platforms and to include them in building management via BMS.

Modern, efficient, and powerful facility management of smart buildings must therefore be based on the use of 3 core systems - BMS, BIM and CAFM (Computer Aided Facility Management). With their use, the cost of operating and maintaining the building can be reduced by up to $30 \%$ and, on the contrary, increasing the usability of the space and the space by more than $15 \%$, ensuring a comfortable indoor environment and thus user satisfaction, as well as maintaining the value of the property and thus the satisfaction of the owners. In spite of some unresolved complications in the field of data transfer support and analysis for large buildings, the complex facility management is a precondition for optimizing the operation of smart buildings.

\section{Case study of a building changed into an intelligent building}

The above mentioned problem can be demonstrated in the example of a kindergarten building and its modernization and reconstruction into a multifunctional building in the possession of a village of about 1,000 inhabitants. As part of the extensive construction modifications, the buildings have been reconstructed several times. Its enriched space has increased by almost $50 \%$, and it also includes the first elementary school and spaces for community use (see Fig. 4). The aim of the building was to expand its capacity and usage while maintaining or even reducing of operating costs, 


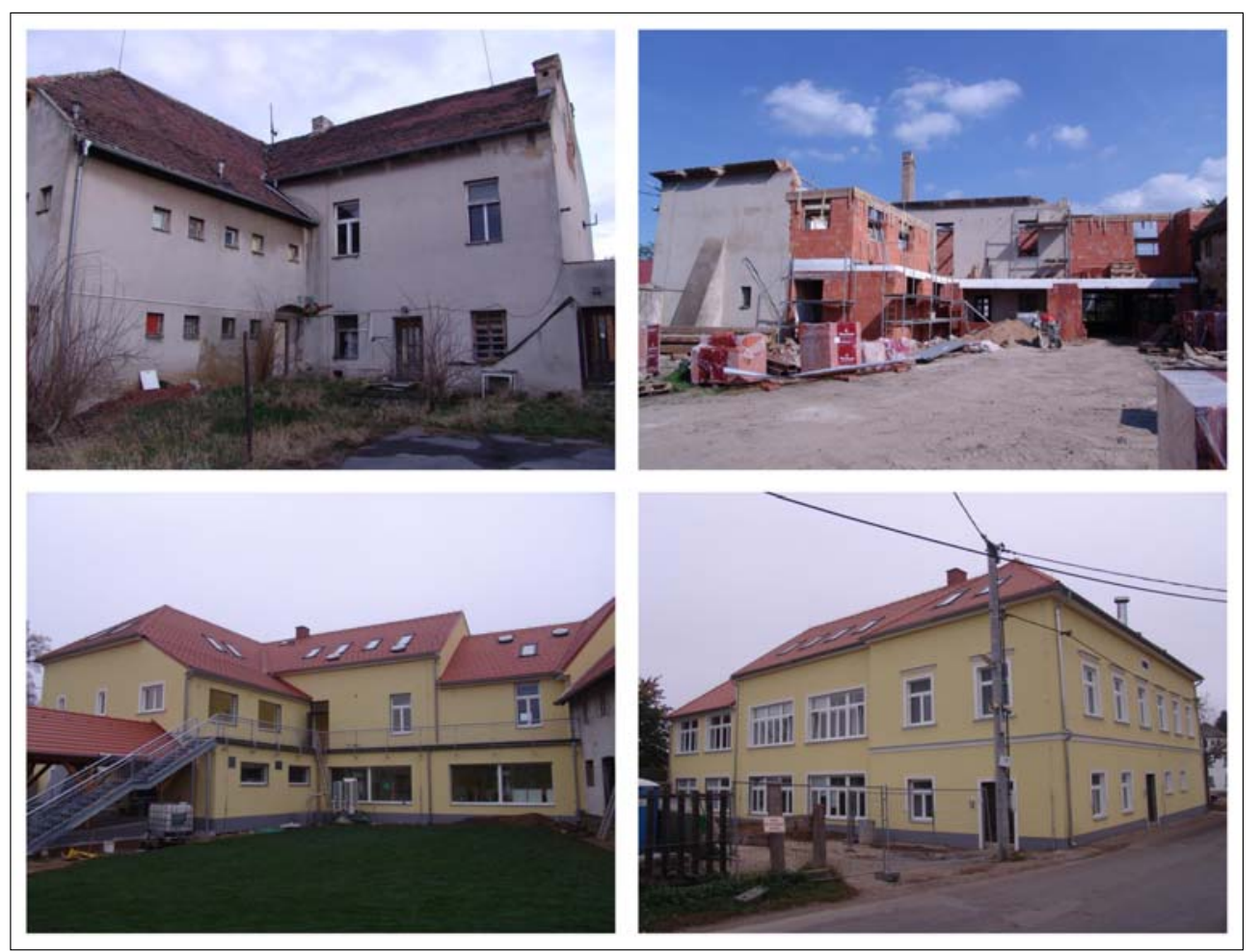

Fig. 4. Initial state, implementation phase and new building status

in particular: the removal of a number of defects and failures of structures; improvement of the quality of the indoor environment and increased safety of operation and fire safety of the building. The general designer of the construction at the same time carried out technical supervision and in all phases were respected the requirements for future use and efficient building facility management.

The energy intensity of the original building was rated as "very uneconomic", total energy delivered $233 \mathrm{kWh} /\left(\mathrm{m}^{2}\right.$.year). The energy sources were following: solar and environment energy $-12 \%$; energy based on electricity and solid fuels $-88 \%$. After the modifications the building achieved the classification "very economical" $\left(58 \mathrm{kWh} /\left(\mathrm{m}^{2}\right.\right.$.year $)$. The ratio of the energy sources were: $52 \%$ the solar and environment energy and $48 \%$ the electricity.

These energy parameters were achieved with high quality of ETICS insulation, insulating parameters of window fillings, energy-saving lighting fixtures and appliances in both food preparations, heating and water heating with two air-to-water heat pumps, two forced ventilation units with heat recovery, environmental parameter sensors inside and outside the building, a solar blind system for selected windows and the registration of movement of people inside the building.

The user registration system is an essential element of the solution. 5 groups of users are distinguished: 1. management (director, municipal representatives), 2. pedagogical staff, 3. auxiliaries (maintenance, cleaning, preparation of meals), 4. parents of children in nursery school, 5 . children in elementary school, who were distinguished by means of chips controlling the main entrance to the building.

In the central BMS system for heating, ventilation and lighting of individual building components (kindergarten, elementary school, public spaces), each group of chips has specific rights set. For example, in a situation where only cleaning workers are indoors, heating and ventilation are left in a standby mode; in case of the presence of one of the managers, the heating and ventilation of selected rooms are in the operating mode, for instance for the needs of working meetings. Apart from the exceptions, the building's conference rooms will not be used at the same time as the primary school premises - the capacity of heating and ventilation is thus only designed for alternating mode, which has reduced the acquisition costs and, in part, the operating costs. If both spaces are used concurrently, the BMS must ensure adequate ventilation and heating, depending on the current capacity reserve.

An inexcusable complication in the design and implementation of the building intelligence system was the fact that the construction project was supported by a special purpose subsidy. As part of the project preparation, it was neither possible to define a specific BMS supplier and build the system; it was only possible to specify very precisely its required parameters. The tenderers of the contractor had very different systems in their offers. The system actually delivered had to be modified for technical reasons even after the construction started. In particular, it was about eliminat- 
ing conflicts in BMS communication and individual technologies, such as a chip terminal, including the individual setting of the ,rights" of each chip in the presence of multiple people with different rights in the building, different ventilation and heating modes only of partial areas outside the normal operating mode, solar blinds on the sunny side of the building with ventilation unit control and heating, a relatively large number of possible combinations of modes of individual technologies (currently more than 100).

The fundamental difference from the original state is a complete change in the way the building is managed. Initially, the care of the building was limited mainly for cleaning and relatively normal maintenance of the building and relatively simple technologies; all services were provided by workers within the municipality. In its present state it is a sophisticated facility management. Cleaning has become a marginal expertise, the key service is monitoring the use of the building, optimizing the operating parameters of the sophisticated technologies and maintaining them. These activities are already carried out by specialized external companies. Facility management costs are multiplied by the original state, currently exceeding $€ 10,000$ per year. Once the optimal operating parameters of the whole system have been achieved, they can be expected to decrease.

Building management has not yet used the BIM platform, so there is no BMS and BIM compatibility experience. Over the next few years, it can be assumed the transition to BIM, eventual conflicts between BIM and BMS platforms will be removed during its implementation. A quantifiable parameter can then also be a comparison of the financial performance and effectiveness of building management before and after the introduction of the BIM platform and its presentation to the professional public.

In spite of some of the shortcomings and complications described above, compared to the original condition after a few years of operation, a reduction in annual energy costs of more than $€ 20,000$ may be noted, despite the increased use of the building and the increase in the total energy related area of the building by $48 \%$ to $1252 \mathrm{~m}^{2}$. The savings are approximately $25 \%$ more optimistic than the calculation values set in the project preparation. After deducting known and estimated costs for ongoing maintenance of intelligent building technologies and other related costs, operating cost savings are approximately half. A comprehensive financial analysis shows that the payback time for the intelligent system should be 10 years at the most.

\section{Conclusion}

The phenomenon of smart buildings has brought the requirement to change the facility management con- cept to the management of real estate. While preventing a traditional approach, smartness (intelligence) of building is rather a disadvantage - due to the large amount of embedded technology systems. The result is not only an increase in the operational performance of the building and a deterioration in the ease of use, but also a threat to the productivity and health of its users, as well as an increase in total operating costs. Hiring an expertly capable facility manager for smart building management is the responsibility of the owner.

The facility manager must possess a high professional ability not only in technical and non-technical disciplines, but also in working with large volumes of data, its management, analysis, evaluation and application in practice in the management of building intelligence systems. Taking into account that the expected lifetime of buildings is around 80 years, it is also possible to assume during the lifecycle the rapid technological development of these systems. The development of these systems will come with the necessity of their continuous renewal and involvement in the central management system in order to operate the building and to ensure the requirements of owners and users. Both BMS platforms and buildings owners through facility managers, on the one hand, bring a high degree of flexibility, investment protection, convenience in providing traffic information, and freedom of decision-making; on the other hand, they bring new requirements for expertise and access to building management. The main difference from the established procedures is indeed an individual approach to each building and its users. The routine is no longer admissible.

\section{Acknowledgements}

The research work presented in this article was supported by the Project SGS-2016-038.

\section{References}

[1] Teicholz E. (2001), Facility Design and Management Handbook. 1st ed., The McGraw-Hill Companies, Inc., New York.

[2] Pasek J., Matouskova I., Ort P., Chlubna V., Cupal M., Kolarova L., Tvrznikova D., Horak J. (2016), Analysis of the Relationship of the System "Operationally Efficient Building - Indoor Environment Quality - User”. In: Applied Mechanics and Materials (Volume 824), Trans Tech Publications Inc., Switzerland, pp. 199-209.

[3] Information on http://cife.stanford.edu/Publications/ index.html. CIFE Technical Reports, November 22, 2007.

[4] CSN EN 15221-1 Facility Management - Part 1: Terms and Definitions, UNMZ, Prague, 2014. 